\title{
ESTRATÉGIA DE FORNECIMENTO DE CONCENTRADO PARA VACAS DA RAÇA HOLANDESA EM PASTAGEM DE COAST-CROSS ${ }^{1}$
}

\author{
MAURILIO JOSÉ ALVIM², RUI DA SILVA VERNEQUE ${ }^{3}$, DUARTE VILELA ${ }^{3}$, ANTONIO CARLOS CÓSER ${ }^{3}$, \\ MILTON DE ANDRADE BOTREL ${ }^{4} \mathrm{e}$ GISELE MARIA REZENDE ${ }^{5}$
} RESUMO - O experimento foi conduzido na Embrapa-Centro Nacional de Pesquisa de Gado de Leite,
Coronel Pacheco, MG, objetivando avaliar formas de fornecer $6 \mathrm{~kg}$ de concentrado para vacas em
pastagem de coast-cross: A - quantidade fixa, e B - quantidade variável $(9,6$ e $3 \mathrm{~kg} / \mathrm{vaca} / \mathrm{dia}$,
respectivamente na primeira, segunda e terceira fase da lactação). O delineamento foi o de blocos ao
acaso e duas repetições de pastagem, com os tratamentos organizados em parcelas divididas. Nas
parcelas, consideraram-se os critérios de distribuição de ração, e nas subparcelas, as fases de lactação.
O fornecimento variável de concentrado favoreceu $(\mathrm{P}<0,05)$ a taxa de lotação da pastagem na
primeira fase de avaliação. As produções diárias de leite obtidas foram de $21,5( \pm 2,8)$ e
$25,5( \pm 2,6) \mathrm{kg} / \mathrm{vaca}(\mathrm{P}<0,05), 64,5( \pm 7,1)$ e $96,9( \pm 10,3) \mathrm{kg} / \mathrm{ha}(\mathrm{P}<005)$, na primeira fase de avaliação;
$19,8( \pm 2,4)$ e $20,6( \pm 2,3) \mathrm{kg} / \mathrm{vaca}(\mathrm{P}>0,05), 93,1( \pm 10,8)$ e $94,8( \pm 10,9) \mathrm{kg} / \mathrm{ha}(\mathrm{P}>0,05)$ na segunda;
$14,2( \pm 2,2)$ e $13,4( \pm 2,3) \mathrm{kg} / \mathrm{vaca}(\mathrm{P}>0,05)$ e $102,2( \pm 12,4)$ e $93,8( \pm 10,5) \mathrm{kg} /$ ha $(\mathrm{P}>0,05)$ na terceira,
respectivamente em relação a A e B. A dose variável mostrou ser a mais indicada para suplementar vacas
Holandesas em pastagem coast-cross.

Termos para indexação: consumo de forragem, Cynodon dactylon, pastejo, produção de leite, taxa de lotação.

\section{STRATEGY OF GIVING CONCENTRATE TO LACTATING HOLSTEIN COWS GRAZING COAST-CROSS PASTURE}

\begin{abstract}
The trial was carried out at the Embrapa-Centro Nacional de Pesquisa de Gado de Leite, at Coronel Pacheco, Brazil, to evaluate two ways of feeding $6 \mathrm{~kg} /$ day of a concentrate mixture to cows grazing a coast-cross pasture: A - a fixed amount, and B - a variable amount $(9,6$ and $3 \mathrm{~kg} / \mathrm{cow} /$ day for the first, second, and third stage of lactation). A randomized block design was used with two replications for land grazing area, with the treatments organized in split plots. In the plots, the ways of feeding of distributing the ration concentrate were considered, and in the split plots, the phases of lactation were used. Feeding variable amount of concentrate affected $(\mathrm{P}<0.05)$ pasture stocking rate only in the first stage of lactation. Milk productions were $21.5( \pm 2.8)$ and $25.5( \pm 2.6) \mathrm{kg} / \mathrm{cow}(\mathrm{P}<0.05), 64.5( \pm 7.1)$ and $96.9( \pm 10.3) \mathrm{kg} / \mathrm{ha}(\mathrm{P}<0.05)$ in the first phase of lactation; $19.8( \pm 2.4)$ and $20.6( \pm 2.3) \mathrm{kg} / \mathrm{cow}$ $(\mathrm{P}>0.05), 93.1( \pm 10.8)$ and $94.8( \pm 10.9) \mathrm{kg} / \mathrm{ha}(\mathrm{P}>0.05)$ in the second phase; $14.2( \pm 2.2)$ and $13.4( \pm 2.3) \mathrm{kg} / \mathrm{cow}(\mathrm{P}>005)$ and $102.2( \pm 12.4)$ and $93.8( \pm 10.5) \mathrm{kg} / \mathrm{ha}(\mathrm{P}>0.05)$ in the last phase, respectively for A and $\mathrm{B}$. The variable dose was the best indicated to supplement Holstein dairy cows in coast-cross pasture.
\end{abstract}

Index terms: forrage consumption, Cynodon dactylon, grazing, milk production, stocking rate.

${ }^{1}$ Aceito para publicação em 24 de setembro de 1998.

${ }^{2}$ Zoot., M.Sc., Embrapa-Centro Nacional de Pesquisa de Gado de Leite (CNPGL), Rua Eugênio do Nascimento, 610, Dom Bosco, CEP 36038-330 Juiz de Fora, MG. Bolsista do CNPq. E-mail: alvim@cnpgl.embrapa.br

${ }^{3}$ Eng. Agr., Ph.D., Embrapa-CNPGL. Bolsista do CNPq. E-mail: rsverneq@cnpgl.embrapa.br; coser@cnpgl.embrapa.br; duarte@cnpgl.embrapa.br

${ }^{4}$ Eng. Agr., M.Sc., Embrapa-CNPGL. Bolsista do CNPq. E-mail: mbotrel@cnpgl.embrapa.br

${ }^{5}$ Zoot., Rua Missemo de Pádua 220/204, Centro, CEP 37200-000 Lavras, MG. Bolsista do CNPq.

\section{INTRODUÇÃO}

Constata-se atualmente no Brasil tendência de maior especialização dos sistemas de produção de leite, nos quais sejam usados animais de potencial genético elevado. Segundo Botrel et al. (1994), essa especialização ocorre principalmente nas regiões Sul e Sudeste, onde se encontram as principais bacias leiteiras do país. Diante disso, aumenta a demanda por informações sobre volumosos de boa qualidade, capazes de reduzir os custos da alimentação. 
alimentos eficientes para vacas em lactação, possibilitando alcançar produções de leite em quantidades entre 15 e $22 \mathrm{t} / \mathrm{ha} / \mathrm{ano}$. Conforme Assis (1982), em sistemas de produção de leite menos intensivos, nos quais os animais têm acesso às pastagens, a alimentação animal é de custo menor do que em sistemas mais intensivos, onde os animais são mantidos estabulados. Para Matos (1995), no caso do Brasil, o setor leiteiro deve levar em consideração a existência de área territorial extensa, de clima predominantemente tropical, favorável à produção de biomassa pelas gramíneas do grupo $\mathrm{C} 4$.

Vilela et al. (1996) e Alvim et al. (1997) avaliaram a alternativa de intensificação da produção de leite de vacas da raça Holandesa com potencial genético para produzir de 6 a $7 \mathrm{mil} \mathrm{kg} /$ lactação, mantidas em pastagem de coast-cross, irrigada e adubada, registrando produções próximas de 17 e de $20 \mathrm{~kg} / \mathrm{vaca} / \mathrm{dia}$, respectivamente quando os animais receberam 3 ou $6 \mathrm{~kg} / \mathrm{dia}$ de concentrado. Esses autores mostraram que a alimentação das vacas na pastagem recebendo $3 \mathrm{~kg}$ de concentrado teve custo menor do que a de vacas em confinamento. A capacidade de suporte da pastagem atingiu, em média, 5,5 vacas/ha. Os autores concluíram que pastagem de coast-cross constitui alternativa economicamente viável para alimentar vacas da raça Holandesa em lactação e garantir a intensificação da produção de leite na pastagem.

O uso de concentrado na dieta de vacas em lactação assume maior ou menor importância, em razão do potencial de produção de leite do animal e da fase de lactação em que estes se encontram. Martinez et al. (1980) e Cowan (1996) afirmaram que o limite de produção de leite de vacas em pastagens tropicais não ultrapassa a $4.500 \mathrm{~kg} / \mathrm{vaca} /$ lactação, sendo esse limite determinado pelo conteúdo alto de fibra e pela digestibilidade baixa do pasto. Em sistemas de produtividade superior, é fundamental que se recorra à suplementação com concentrados. Estes, em relação aos suplementos volumosos, apresentam maior concentração energética e são economicamente competitivos, por apresentarem baixos incrementos calóricos, quando estrategicamente usados. Moreira (1984) informou que o fornecimento de concentrado em quantidade fixa pode subalimentar as vacas mais produtivas, com prejuízos para a produção de leite, e superalimentar as menos produtivas, podendo elevar os custos dos sistemas de produção. A avaliação da economicidade no uso de concentrados está diretamente relacionada com a qualidade do pasto e com o potencial genético dos animais. Davidson (1990) afirmou que o uso de concentrados também está relacionado ao seu custo e à quantidade utilizada, com a margem líquida, sendo crescente e positiva à medida que for menor o preço de concentrado e maior a produção de leite.

Neste estudo, avaliou-se a eficiência de distribuição estratégica de $6 \mathrm{~kg} / \mathrm{vaca} / \mathrm{dia}$ de concentrado para vacas da raça Holandesa em pastagem de coast-cross, objetivando a intensificação da produção de leite.

\section{MATERIAL E MÉTODOS}

O experimento foi conduzido em áreas da Embrapa-Centro Nacional de Pesquisa de Gado de Leite, em Coronel Pacheco, MG, $\left(21^{\circ} 33^{\prime} 22^{\prime \prime}\right.$ de latitude S e $43^{\circ} 6^{\prime} 15^{\prime \prime}$ de longitude O), no período de 15.5.1995 a 9.2.1996 (40 semanas). O clima da região é do tipo Cwa (mesotérmico), definido como temperado, chuvoso no verão e seco no inverno. A precipitação média anual está ao redor de $1.500 \mathrm{~mm}$, distribuídos irregularmente, com cerca de $200 \mathrm{~mm}$ de precipitação que ocorre no período da seca (maio a setembro). Foram comparadas duas formas de fornecimento diário de $6 \mathrm{~kg}$ de concentrado para vacas Holandesas em pastagem de coast-cross, que constituíram os tratamentos: A - quantidade fixa durante todo o período de avaliação (270 dias de lactação), e B - quantidade variável, sendo $9 \mathrm{~kg}$ nos primeiros 90 dias da avaliação, $6 \mathrm{~kg}$ nos 90 dias seguintes e $3 \mathrm{~kg}$ nos últimos 90 dias. Em ambas as formas, a quantidade total de concentrado fornecida para cada animal foi a mesma (1.620 kg/vaca/270 dias).

Foram usadas 16 vacas PO e PC (oito por tratamento), da primeira à quarta lactação, com potencial de produção de leite de $6.000 \mathrm{~kg}$ /lactação e apresentando de 35 a 45 dias após o parto.

A pastagem de coast-cross estava localizada em área plana de várzea, em solo classificado como aluvial eutrófico, que ao iniciar as avaliações apresentava, na camada superficial de $20 \mathrm{~cm}$, as seguintes características químicas: $\mathrm{pH}$ em água $(1: 2,5)=6,1 ; \mathrm{P}=19,4 \mathrm{ppm} ; \mathrm{K}=96,2 \mathrm{ppm}$; $\mathrm{Al}=0,2 \mathrm{meq} / 100 \mathrm{~g} ; \mathrm{Ca}=4,3 \mathrm{meq} / 100 \mathrm{~g} ; \mathrm{Mg}=1,9 \mathrm{meq} / 100 \mathrm{~g}$; e $\mathrm{MO}=2,8 \%$. 
A adubação realizada durante a condução do experimento foi de $280 \mathrm{~kg} / \mathrm{ha}$ de $\mathrm{N}, 70 \mathrm{~kg} / \mathrm{ha}$ de $\mathrm{P}_{2} \mathrm{O}_{5}$ e $224 \mathrm{~kg} / \mathrm{ha}$ de $\mathrm{K}_{2} \mathrm{O}$, fracionados em aplicações mensais, realizadas em cobertura. Nos meses de junho a outubro, a pastagem foi irrigada por aspersão a cada 15 dias, com a lâmina de água correspondendo a 35-45 mm.

A área total da pastagem foi de quatro hectares, dividida em duas repetições/tratamento, sendo a área de cada repetição igual a um hectare. Em cada repetição foram usadas quatro vacas experimentais, com média de peso de $550 \mathrm{~kg} / \mathrm{vaca}$. Para obter equilíbrio de forragem residual na pastagem, nas épocas de maior crescimento da forrageira, foram usadas vacas extras em lactação e de potencial produtivo semelhante ao das vacas experimentais.

A área de cada repetição foi dividida por cerca elétrica em 33 piquetes de $300 \mathrm{~m}^{2}$, no período de $15 / 5$ a 30/9/95 (época da seca e de baixa temperatura), e em 25 piquetes de $400 \mathrm{~m}^{2}$, no período de $1 / 10 / 95$ a $7 / 2 / 96$ (época das chuvas e de temperatura elevada). Adotou-se o pastejo rotativo, sempre com um dia de ocupação do piquete e 32 e 24 dias de descanso nos períodos da seca e das chuvas, respectivamente.

Foram estimadas semanalmente, antes e após o pastejo, as quantidades de forragem disponível e residual da pastagem. Estas se basearam na quantidade de forragem cortada antes (forragem disponível) e após (forragem residual) o pastejo, a $8 \mathrm{~cm}$ acima do nível do solo, e retirada do interior de um quadrado de $1 \mathrm{~m}$ de lado, lançado ao acaso por três vezes em cada piquete. Toda a vegetação existente abaixo do extrato de $8 \mathrm{~cm}$ foi desconsiderada. Parte da forragem colhida foi levada ao laboratório para estimar a qualidade da forragem, com base nos teores de proteína bruta, fibra em detergente neutro, e digestibilidade in vitro da matéria seca. No período experimental, a presença de plantas invasoras na pastagem oscilou de $9 \%$ na época da seca a $3 \%$ na época das chuvas.

A estimativa do consumo diário de matéria seca de coast-cross pelos animais no pasto foi obtida pela diferença entre as quantidades de matéria seca disponível e residual do piquete, dividida pela taxa de lotação momentânea da pastagem (vacas experimentais e vacas extras).

O concentrado fornecido às vacas foi constituído de $48 \%$ de fubá de milho, $35 \%$ de farelo de soja, $15 \%$ de farelo de trigo, $1 \%$ de calcário calcítico e $1 \%$ de mistura mineral, apresentando $92 \%$ de MS, $23,5 \%$ de PB e $80 \%$ de NDT. Na primeira fase de avaliação (período de 0 a 90 dias), foi adicionado a esse concentrado $1 \%$ de bicarbonato de sódio.
No período experimental as vacas tiveram acesso livre à sombra artificial. Nos dias quentes, por volta das $13 \mathrm{~h}$, esses animais foram recolhidos ao estábulo provido de bebedouros e cochos com mistura mineral, situado próximo à sala de ordenha. As vacas foram ordenhadas duas vezes ao dia e, apesar de apresentarem cios, não foram inseminadas durante o período experimental.

Os dados obtidos de cada tratamento foram organizados em três fases de lactação de 90 dias cada, e analisados conforme o delineamento de blocos ao acaso, com parcelas divididas; na parcela foram alocados os dois critérios de fornecimento de concentrado, e na subparcela, as três fases de lactação. A unidade de observação foi representada pela vaca. No período experimental completo considerou-se o delineamento em blocos casualizados com duas repetições de pastagem e oito vacas por tratamento. Foi proposto o seguinte modelo de regressão não-linear para se ajustar à curva de produção de leite observada nos dois tratamentos avaliados:

$\mathrm{PL}=\mathrm{A}(\mathrm{X}+1)^{\mathrm{B}} \exp (-\mathrm{C}(\mathrm{X}+1))+\varepsilon$, sendo, PL a produção de leite de cada vaca na data de controle $(0,30,60,90,120,150,180,210,240$ e 270 dias da lactação); X o período experimental até cada data de controle e A, B e C os parâmetros do modelo que devem ser estimados.

\section{RESULTADOS E DISCUSSÃO}

As produções de leite registradas diariamente foram de $21,5( \pm 2,8)$ e $25,5( \pm 2,6) \mathrm{kg} / \mathrm{vaca} / \mathrm{dia}$, nos primeiros 90 dias de avaliação, 19,8 $( \pm 2,4)$ e $20,6( \pm 2,3) \mathrm{kg} / \mathrm{vaca} / \mathrm{dia}$, nos 90 dias seguintes, e $14,2( \pm 2,2)$ e $13,4( \pm 2,3) \mathrm{kg} / \mathrm{vaca} / \mathrm{dia}$, nos últimos 90 dias, com a média referente a todo o período experimental (270 dias), sendo de 18,5 $( \pm 3,1)$ e $19,8( \pm 3,4) \mathrm{kg} / \mathrm{vaca} / \mathrm{dia}$, respectivamente ao se fornecer para os animais concentrado em quantidades fixas ou variáveis (Tabela 1). Esses resultados mostram que o fornecimento de concentrado em quantidade variável favoreceu $(\mathrm{P}<0,05)$ a média da produção de leite ( $\mathrm{kg} / \mathrm{vaca} / \mathrm{dia})$ apenas nos primeiros 90 dias de avaliação, não tendo sido verificados $(P>0,05)$ efeitos entre tratamentos sobre as médias das produções alcançadas nas demais fases de avaliação e na média de todo o período experimental. Na primeira fase de avaliação, teoricamente, a dieta completa (pasto + concentrado) dos animais que receberam $9 \mathrm{~kg} / \mathrm{vaca} / \mathrm{dia}$ de con-

Pesq. agropec. bras., Brasília, v.34, n.9, p.1711-1720, set. 1999 
centrado foi de melhor qualidade (proteína bruta e energia) do que a do grupo que recebeu $6 \mathrm{~kg} / \mathrm{vaca} / \mathrm{dia}$. Conseqüentemente, a diferença na produção de leite $(\mathrm{kg} / \mathrm{vaca} / \mathrm{dia})$ obtida nesta fase de avaliação foi reflexo da diferença de qualidade da dieta que as vacas receberam.

$\mathrm{O}$ fornecimento de dieta de melhor qualidade para vacas de produção alta em início de lactação é recomendada por Cowan (1996) e Matos (1995). Por outro lado, na última fase de avaliação, apesar de existir diferença na quantidade de concentrado fornecida aos animais, houve semelhança $(\mathrm{P}>0,05)$ entre as produções médias de leite ( $\mathrm{kg} / \mathrm{vaca} / \mathrm{dia})$. Neste caso, é provável que o fornecimento de $3 \mathrm{~kg}$ de concentrado associado à melhor qualidade do pasto, verificada durante essa fase de avaliação (Tabela 2), pode ter sido suficiente para garantir a produção de leite das vacas, já em fase final da lactação.

Vilela et al. (1996) e Alvim et al. (1997) confirmaram o potencial forrageiro elevado do coast-cross, observando-se, na fase final da lactação, produções de leite em quantidade próxima de $14 \mathrm{~kg} / \mathrm{vaca} /$ dia. Naqueles experimentos, foram usadas vacas da raça Holandesa, que, além do pasto, receberam $3 \mathrm{~kg}$ de concentrado. Os teores de proteína bruta, fibra em detergente neutro e digestibilidade in vitro da matéria seca da forragem de coast-cross foram altos ao longo do ano, com variações entre 15,5 e 20,0\%, 53 e 60,5\% e 64,5 e $68,5 \%$, respectivamente.

As duas estratégias de suplementação estudadas provocaram modificações nas curvas de produção de leite das vacas em pastagem de coast-cross. Ao fixar a quantidade de concentrado, observou-se, nos primeiros 90 dias, queda $(\mathrm{P}<0,05)$ imediata na curva de produção de leite ( $\mathrm{kg} / \mathrm{vaca} / \mathrm{dia})$, ao passo que, variando a quantidade de concentrado, obteve-se melhor estabilidade na produção nessa primeira fase de avaliação, e a partir daí, as curvas de produção de leite se aproximaram. A Fig. 1 apresenta os pontos de produção de leite observados e as curvas de produção de leite ajustadas por tratamento conforme modelo de regressão proposto. As equações de regressão ajustadas por tratamento foram: ao fornecer concentrado para os animais em dose variável,

$\mathrm{PL}=27,01(\mathrm{X}+1)^{0,0416} \exp (-0,0039(\mathrm{X}+1))$;

ao fornecer concentrado para os animais em dose fixa,

$\mathrm{PL}=26,81(\mathrm{X}+1)^{-0,0358} \exp (-0,0019(\mathrm{X}+1))$.

Em relação ao fornecimento de concentrado em quantidade fixa, a suplementação em dose variável prolongou o pico de produção de leite, porém, com queda mais acentuada no período subseqüente, o que coincide com as informações de Taylor \& Leaver

TABELA 1. Médias de produção de leite (kg/vaca/dia) e produções acumuladas de leite (kg/vaca/período) com $4 \%$ de gordura, conforme estratégia de fornecimento de concentrado a vacas da raça Holandesa em pastagem de coast-cross. Médias de oito vacas ${ }^{1}$.

\begin{tabular}{|c|c|c|c|c|}
\hline \multirow{2}{*}{$\begin{array}{c}\text { Período de } \\
\text { avaliação (dias) }\end{array}$} & \multicolumn{4}{|c|}{ Quantidade de concentrado (kg/vaca/dia) } \\
\hline & Fixa & Variável & Fixa & Variável \\
\hline & \multicolumn{2}{|c|}{-----------Leite (kg/vaca/dia)---------. } & \multicolumn{2}{|c|}{-------------Leite (kg/vaca/período)------- } \\
\hline. .0 a 90 & $21,5 \mathrm{bA}(2,8)^{2}$ & $25,5 \mathrm{aA}(2,6)$ & $1.935 \mathrm{bA}(303,4)$ & $2.295 \mathrm{aA}(345,5)$ \\
\hline 91 a 180 & $19,8 \mathrm{aA}(2,4)$ & $20,6 \mathrm{aB}(2,3)$ & $1.782 \mathrm{aA}(287,1)$ & $1.854 \mathrm{aB}(333,9)$ \\
\hline 181 a 270 & $14,2 \mathrm{aB}(2,2)$ & $13,4 \mathrm{aC}(2,3)$ & $1.278 \mathrm{aB}(242,7)$ & $1.206 \mathrm{aC}(204,2)$ \\
\hline Média $^{3}$ & $18,5 \mathrm{a}(3,1)$ & $19,8 \mathrm{a}(3,4)$ & & \\
\hline Total $^{3}$ & - & - & $4.995 \mathrm{a}(612,8)$ & $5.355 \mathrm{a}(719,0)$ \\
\hline C.V. $(\%)$ & 14,8 & 12,7 & 18,9 & 17,5 \\
\hline
\end{tabular}

${ }^{1}$ Médias seguidas da mesma letra, minúscula na linha e maiúscula na coluna, não diferem entre si, pelo teste de Tukey a 5\% de probabilidade.

2 Valores entre parênteses correspondem ao erro-padrão da média.

3 Valores relativos ao período completo de avaliação (270 dias). 
TABELA 2. Porcentagem de matéria seca (MS), proteína bruta $(\mathrm{PB})$, fibra em detergente neutro (FDN) e digestibilidade in vitro da MS disponível e residual na pastagem de coast-cross (média dos dois tratamentos avaliados).

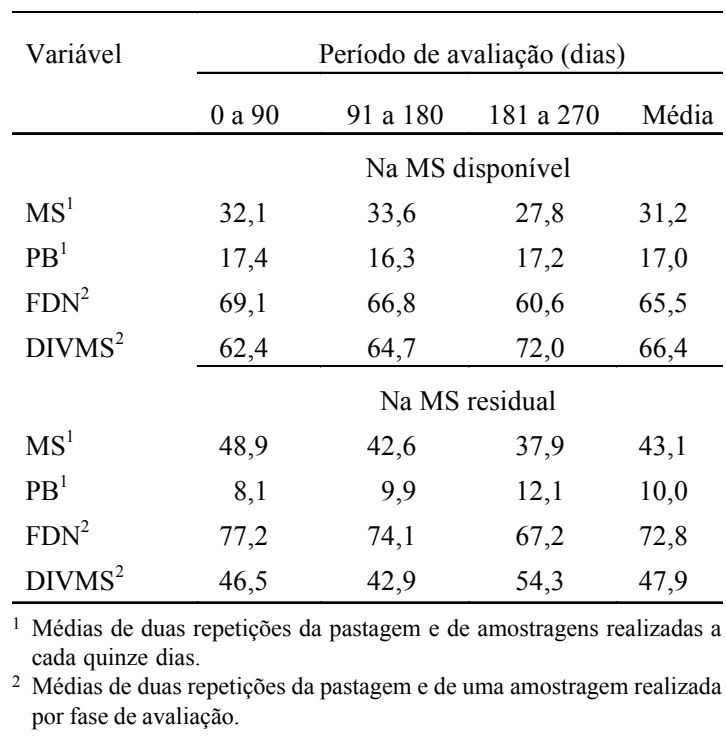

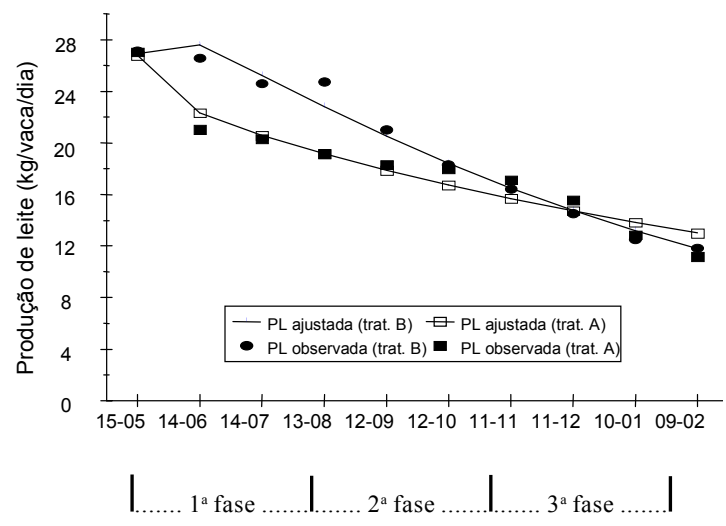

FIG. 1. Curvas de produção de leite (PL) ajustadas, conforme estratégia de fornecimento de concentrado a vacas da raça Holandesa em pastagem de coast-cross (tratamento A: concentrado em quantidade fixa; tratamento B: concentrado em quantidade variável).
(1984). Portanto, as curvas de produção de leite registradas foram inicialmente influenciadas pela quantidade de concentrado que as vacas receberam na fase inicial da lactação.

Em Cuba, Martinez et al. (1980) estudaram os efeitos de diferentes estratégias de fornecimento de concentrado para vacas da raça Holandesa em pastagem de coast-cross sobre a produção de leite. As seguintes dietas foram comparadas: a) somente pastagem; b) fornecimento de $0,5 \mathrm{~kg} / \mathrm{vaca} / \mathrm{dia}$ de concentrado para cada litro de leite produzido diariamente nas seguintes condições: 1- acima do décimo dia; 2 - acima do quinto e 3 - acima do quinto, mas somente nas dez primeiras semanas de lactação. Esses autores não verificaram diferenças acentuadas na produção de leite ao longo de toda a lactação, e registraram médias variando de 13,1 a $13,8 \mathrm{~kg} / \mathrm{vaca} / \mathrm{dia}$. Os autores justificaram a semelhança entre as produções de leite em função da elevada qualidade da forragem disponível nas pastagens de coast-cross, com o teor de proteína bruta superior a $25 \%$. No presente trabalho, apesar de a forragem disponível para os animais ter sido de qualidade inferior, as médias de produção de leite, em $\mathrm{kg} / \mathrm{vaca} / \mathrm{dia}$, foram superiores às obtidas por Martinez et al. (1980). Sobre isso, deve-se levar em consideração, além da ocorrência de diferentes condições edafoclimáticas predominantes nas regiões onde os experimentos foram conduzidos, que as vacas deste experimento foram de potencial de produção de leite mais elevado e receberam maior quantidade de concentrado que as do experimento de Martinez et al. (1980). Vilela et al. (1996) avaliaram a produção de leite de vacas da raça Holandesa em pastagem de coast-cross, irrigada durante a época da seca e fornecendo aos animais em pastejo $3 \mathrm{~kg} / \mathrm{vaca} /$ dia de concentrado. A produção média de leite correspondente aos 280 dias de avaliação foi de $16,6 \mathrm{~kg} / \mathrm{vaca} /$ dia, com a média dos últimos 100 dias de lactação sendo de $12,1 \mathrm{~kg} / \mathrm{vaca} / \mathrm{dia}$. Nas mesmas condições de pastagem, porém fornecendo aos animais $6 \mathrm{~kg} / \mathrm{vaca} / \mathrm{dia}$ de concentrado, Alvim et al. (1997) registraram médias de produções de leite em quantidades próximas de $19,5 \mathrm{~kg} / \mathrm{vaca} / \mathrm{dia}$, na época da seca, e $20,5 \mathrm{~kg} / \mathrm{vaca} / \mathrm{dia}$, na época das chuvas. Devido à maior quantidade de concentrado recebida pelos animais, 
as médias de produções de leite obtidas no presente estudo são superiores às produções das vacas no pasto de coast-cross registradas por Vilela et al. (1996). Por outro lado, são semelhantes às médias de produções alcançadas por Alvim et al. (1997), com as pequenas diferenças sendo justificadas por se tratar de outros animais e de diferentes períodos de avaliação.

As produções de leite acumuladas por fase de avaliação corresponderam a $1.935( \pm 303,4)$ e $2.295( \pm 345,5) \mathrm{kg} / \mathrm{vaca} / 90$ dias, na primeira fase, $1.782( \pm 287,1)$ e $1.854( \pm 333,9) \mathrm{kg} / \mathrm{vaca} / 90$ dias, na segunda fase, e $1.278( \pm 242,7)$ e $1.206( \pm 204,2)$ $\mathrm{kg} / \mathrm{vaca} / 90$ dias, na última fase, totalizando $4.995( \pm 612,8)$ e $5.355( \pm 719,0) \mathrm{kg} / \mathrm{vaca} / 270 \mathrm{dias}$, respectivamente ao se fornecer para as vacas concentrado em quantidades fixas e variáveis (Tabela 1). Essas produções foram expressivas e refletiram as mesmas diferenças observadas nas produções diárias de cada vaca. Embora as médias totais de produções de leite não tenham revelado diferenças estatísticas $(\mathrm{P}>0,05)$, os animais que receberam o concentrado em quantidades estratégicas produziram $360 \mathrm{~kg}$ de leite adicionais em 270 dias (Tabela 1).

As produções de leite registradas em Cuba por Martinez et al. (1980) foram próximas de $1.650 \mathrm{~kg} / \mathrm{vaca} / \mathrm{dia}$, nos primeiros 100 dias de avaliação, $1.300 \mathrm{~kg} / \mathrm{vaca} / \mathrm{dia}$, nos 100 dias seguintes, e $1.250 \mathrm{~kg} / \mathrm{vaca} / \mathrm{dia}$, nos últimos 105 dias, totalizando produções aproximadas de $4.200 \mathrm{~kg} / \mathrm{vaca}$ em 305 dias de lactação, com vacas em regime exclusivo de pastagem de coast-cross, com pequenas variações na produção, em razão de fornecimento de concentrado para os animais. Vilela et al. (1996) registraram, em 280 dias de lactação, produções de $4.648 \mathrm{~kg}$ de leite, com vacas da raça Holandesa em pastagem de coast-cross irrigada na época da seca e suplementadas com $3 \mathrm{~kg}$ fixos de concentrado. Quando suplementadas com $6 \mathrm{~kg}$ fixos de concentrado, Alvim et al. (1997) encontraram produções acumuladas de leite ao redor de $4.300 \mathrm{~kg} / \mathrm{vaca}$, no período das chuvas (sete meses) e de $2.920 \mathrm{~kg}$, no período da seca (cinco meses). Essas produções de leite acumuladas, registradas por Martinez et al. (1980) e por Vilela et al. (1996) são inferiores às obtidas no presente trabalho, onde se registraram, diariamente, maiores produções de leite por vaca, com reflexo positivo na produção por lactação.

O consumo total médio de MS referente ao período experimental foi de 18,2 e 18,8 kg/vaca/dia, respectivamente ao fornecer concentrado para as vacas em quantidades fixas e variáveis, correspondendo, em média, a $3,1 \%$ do peso vivo desses animais (Tabela 3). Foram observadas variações no consumo de MS do pasto, dependendo principalmente da quantidade de concentrado oferecida e da quantidade e qualidade da forragem disponível para os animais (Tabelas 2 e 3). À medida que se diminuiu a quantidade de concentrado ou se aumentou a disponibilidade e qualidade do pasto, o consumo de MS proveniente da pastagem aumentou. No entanto, o consumo total de MS (pasto + concentrado) ao longo do experimento foi adequado para vacas da raça Holandesa, o que indica que não houve restrição de alimento para os animais.

Segundo o National Research Council (1987), de vacas da raça Holandesa com peso vivo médio de $550 \mathrm{~kg}$ e produção de leite entre 15 e $20 \mathrm{~kg} / \mathrm{dia}$, espera-se o consumo de MS variando de 15,5 a $19,7 \mathrm{~kg} / \mathrm{vaca} / \mathrm{dia}$. Arriga-Jordan \& Holmes (1986) encontraram resultados de consumo de matéria seca de vacas da raça Holandesa, mantidas em pastagem, semelhantes aos obtidos no presente trabalho. Segundo Milera et al. (1986, 1987), o consumo de alimento de vacas a pasto é variável, dependendo fundamentalmente da disponibilidade e qualidade da forragem. Esses autores registraram consumo de $16,4 \mathrm{~kg} / \mathrm{vaca} / \mathrm{dia}$ de MS por vacas em pastagem de coast-cross, com disponibilidade de $32 \mathrm{~kg} / \mathrm{vaca}$ de MS e predominância de folhas. Alvim et al. (1997) estimaram o consumo total de $18,8 \mathrm{~kg} / \mathrm{vaca} / \mathrm{dia}$ de MS com vacas no pasto de coast-cross, recebendo $6 \mathrm{~kg}$ fixos de concentrado. Por outro lado, Vilela et al. (1996) registraram, na média de 280 dias de avaliação, o consumo de $14,5 \mathrm{~kg} / \mathrm{vaca} / \mathrm{dia}$ de MS para vacas da raça Holandesa em pastagem de coast-cross recebendo $3 \mathrm{~kg} / \mathrm{vaca} /$ dia de concentrado, com variações expressivas em decorrência da época do ano. Os autores justificaram o baixo consumo de forragem pelos animais, verificado por ocasião das avaliações, em razão da ocorrência de temperaturas e umidade do solo elevadas. 
A taxa de lotação das pastagens de coast-cross, com as vacas sendo suplementadas com concentrado em quantidades fixas e variáveis, foram de $3,0( \pm 0,6)$ e $3,8( \pm 0,6)$ vacas/ha, na primeira fase de avaliação, $4,7( \pm 0,6)$ e $4,6( \pm 0,5)$ vacas/ha, na segunda fase, e 7,2 $( \pm 0,7)$ e $7,0( \pm 0,7)$ vacas/ha, na terceira fase, com a média para o período experimental, sendo de $5,0( \pm 0,3)$ e $5,1( \pm 0,5)$ vacas/ha, respectivamente (Tabela 4). Verificou-se diferença acentuada apenas na primeira fase de avaliação, com a taxa de lotação sendo mais elevada quando o concentrado foi fornecido em quantidade variável. A taxa de lotação da pastagem de coast-cross foi favorecida pela maior quantidade de concentrado que momentaneamente os animais receberam. Entretanto, isso não ocorreu na última fase de avaliação, apesar da diferença na quantidade de concentrado fornecida às vacas nessa época. Pode-se constatar, ainda, que a taxa de lotação da pastagem de coast-cross variou $(\mathrm{P}<0,05)$ entre as três fases de avaliação, foi mais baixa na primeira fase, verificada nos meses de condições climáticas adversas ao crescimento vegetativo da planta, e mais elevada na terceira fase, quando as condições climáticas foram favoráveis. As condições climáticas a partir do mês de agosto foram mais

TABELA 3. Estimativas da matéria seca (MS) disponível e residual (kg/ha) e do consumo de MS (kg/vaca/dia) proveniente do pasto e total por vacas da raça Holandesa em pastagem de coast-cross, conforme estratégia de fornecimento de concentrado.

\begin{tabular}{|c|c|c|}
\hline \multirow[t]{3}{*}{ Variável } & \multicolumn{2}{|c|}{ MS (kg/ha) } \\
\hline & \multicolumn{2}{|c|}{ Quantidade de concentrado $(\mathrm{kg} / \mathrm{vaca} / \mathrm{dia})^{1}$} \\
\hline & Fixa & Variável \\
\hline & \multicolumn{2}{|c|}{0 a 90 dias $(15 / 05$ a $12 / 08 / 95)$} \\
\hline MS disponível & 4.280 & 4.445 \\
\hline MS residual & 3.043 & 3.142 \\
\hline Consumo de pasto & 12,5 & 10,4 \\
\hline \multirow[t]{2}{*}{ Consumo total de MS (pasto + concentrado) } & 18,0 & 18,7 \\
\hline & \multicolumn{2}{|c|}{91 a 180 dias $(13 / 08$ a 10/11/95) } \\
\hline MS disponível & 4.913 & 5.287 \\
\hline MS residual & 3.072 & 3.320 \\
\hline Consumo de pasto & 11,8 & 12,9 \\
\hline \multirow[t]{2}{*}{ Consumo total de MS (pasto + concentrado) } & 17,3 & 18,4 \\
\hline & \multicolumn{2}{|c|}{181 a $270 \operatorname{dias}(09 / 11 / 95$ a 07/02/96) } \\
\hline MS disponível & 5.854 & 6.007 \\
\hline MS residual & 3.450 & 3.405 \\
\hline Consumo de pasto & 13,4 & 14,9 \\
\hline \multirow[t]{2}{*}{ Consumo total de MS (pasto + concentrado) } & 18,9 & 17,7 \\
\hline & \multicolumn{2}{|c|}{ Média $(15 / 05 / 95$ a 07/02/96 - 270 dias $)$} \\
\hline MS disponível & 5.015 & 5.246 \\
\hline MS residual & 3.188 & 3.169 \\
\hline Consumo de pasto & 12,7 & 13,3 \\
\hline Consumo total de MS (pasto + concentrado) & 18,2 & 18,8 \\
\hline
\end{tabular}

\footnotetext{
${ }^{1}$ Ingrediente com $92 \%$ de MS, $23,5 \%$ de PB e $80 \%$ de NDT.
} 
favoráveis para o crescimento vegetativo do coast-cross, adubado e irrigado até o início das chuvas, aumentando, com isso, a disponibilidade de forragem na pastagem (Tabela 3 ) e permitindo, conseqüentemente, aumento expressivo na sua taxa de lotação (Tabela 4). No trabalho de Vilela et al. (1996), a taxa média de lotação da pastagem de coast-cross, irrigada e adubada anualmente com $350 \mathrm{~kg} / \mathrm{ha}$ de $\mathrm{N}$ e $280 \mathrm{~kg} / \mathrm{ha}$ de $\mathrm{K}_{2} \mathrm{O}$, foi de seis vacas/ha, variando conforme a época do ano. O trabalho de Alvim et al. (1997) indicou, para todo o ano, a taxa média de lotação de 4,5 vacas/ha e 5,1 vacas/ha, respectivamente, ao fornecer 3 e $6 \mathrm{~kg}$ de concentrado às vacas em pastejo. Assim, o coast-cross, quando bem manejado, apresenta elevada capacidade de suporte, beneficiando a produção de leite por unidade de área.

As produções diárias de leite obtidas por unidade de área foram de $64,5( \pm 7,1)$ e $96,9( \pm 10,3) \mathrm{kg} / \mathrm{ha}$, nos primeiros 90 dias de avaliação, $93,1( \pm 10,8)$ e $94,8( \pm 10,9) \mathrm{kg} / \mathrm{ha}$, nos 90 dias seguintes, e 102,2 $( \pm 12,4)$ e $93,8( \pm 10,5) \mathrm{kg} / \mathrm{ha}$, nos últimos 90 dias, que, na média para todo o período experimental, corresponderam a 87,3 $( \pm 9,3) \mathrm{e}$ $95,2( \pm 11,3) \mathrm{kg} / \mathrm{ha}$, respectivamente ao fornecer concentrado em quantidades fixas ou variáveis (Tabela 5).
As produções de leite, acumuladas por fase de avaliação, foram elevadas, sendo de $5.805( \pm 416,1) \mathrm{e}$ $8.721( \pm 917,2) \mathrm{kg} / \mathrm{ha} / 90$ dias, na primeira fase de avaliação, $8.379( \pm 612,4)$ e $8.532( \pm 983,4)$ $\mathrm{kg} / \mathrm{ha} / 90$ dias, na segunda fase, e $9.198( \pm 691,5)$ e $8.442( \pm 879,0) \mathrm{kg} / \mathrm{ha} / 90$ dias, na terceira fase, totalizando nos 270 dias de avaliação, produções de leite na ordem de $23.382( \pm 2.901,2)$ e $25.695( \pm 2.912,0) \mathrm{kg} / \mathrm{ha}$, respectivamente nas condições de fornecimento de concentrado em quantidades fixas e variáveis (Tabela 5).

Entre tratamentos, as produções de leite, tanto $\mathrm{em} \mathrm{kg} / \mathrm{ha} / \mathrm{dia}$ como em kg/ha/90 dias, foram diferentes apenas na primeira fase de avaliação, quando as produções das vacas que receberam quantidades estratégicas de concentrado foram mais elevadas $(\mathrm{P}<0,05)$ que as demais. Comparando essas produções, entre fase de avaliação, foram observadas diferenças $(\mathrm{P}<0,05)$ somente nas produções do grupo de vacas que recebeu quantidade fixa de concentrado, sendo as obtidas na primeira fase menores que as demais. Quanto às produções de leite ( $\mathrm{kg} / \mathrm{vaca} / \mathrm{dia}$ e $\mathrm{kg} / \mathrm{ha} / 90$ dias) registradas no grupo de vacas que recebeu concentrado de forma estratégica, notou-se semelhança $(P>0,05)$ entre elas. As produções de leite alcançadas são expressivas e justificam o manejo adotado na pastagem,

TABELA 4. Taxa de lotação (vacas/ha) da pastagem de coast-cross, conforme estratégia de fornecimento de concentrado a vacas da raça Holandesa. Médias de duas repetições de pastagem¹.

\begin{tabular}{cccc}
\hline \multirow{2}{*}{$\begin{array}{c}\text { Período de } \\
\text { avaliação (dias) }\end{array}$} & Época do ano & \multicolumn{2}{c}{ Taxa de lotação (vacas/ha) } \\
\cline { 3 - 4 } & & Quantidade de concentrado (kg/vaca/dia) \\
\cline { 3 - 4 } & & Fixa & Variável \\
\hline 0 a 90 & $(15 / 05 / 95$ a 12/08/95) & $3,0 \mathrm{aC}(0,6)^{2}$ & $3,8 \mathrm{bC}(0,6)$ \\
91 a 180 & $(13 / 08 / 95$ a 10/11/95) & $4,7 \mathrm{aB}(0,6)$ & $7,6 \mathrm{aB}(0,5)$ \\
181 a 270 & $(09 / 11 / 95$ a 07/02/96) & $7,2 \mathrm{aA}(0,7)$ & $5,1 \mathrm{a}(0,5)$ \\
\hline Média $^{3}$ & $(15 / 05 / 95$ a 07/02/96) & $5,0 \mathrm{a}(0,3)$ & 19,2 \\
\hline C.V. $(\%)$ & & 16,1 & \\
\hline
\end{tabular}

${ }^{1}$ Médias seguidas da mesma letra, minúscula na linha e maiúscula na coluna, não diferem entre si, pelo teste de Tukey a 5\% de probabilidade.

${ }^{2}$ Valores entre parênteses correspondem ao erro-padrão da média.

3 Valores relativos ao período completo de avaliação (270 dias). 
TABELA 5. Produções de leite por área (kg/ha/dia e $\mathrm{kg} / \mathrm{ha} /$ período), com $4 \%$ de gordura, conforme estratégia de fornecimento de concentrado a vacas da raça Holandesa em pastagem de coast-cross. Médias de duas repetições de pastagem 1 .

\begin{tabular}{|c|c|c|c|c|}
\hline \multirow{2}{*}{$\begin{array}{l}\text { Período de } \\
\text { avaliação } \\
\text { (dias) }\end{array}$} & \multicolumn{4}{|c|}{ Quantidade de concentrado (kg/vaca/dia) } \\
\hline & Fixa & Variável & Fixa & Variável \\
\hline & \multicolumn{2}{|c|}{----Leite (kg/ha/dia)------- } & \multicolumn{2}{|c|}{---Leite (kg/ha/período)-- } \\
\hline 0 a 90 & $64,5 \mathrm{bB}(7,1)^{2}$ & $96,9 \mathrm{aA}(10,3)$ & $5.805 \mathrm{bB}(416,1)$ & $8.721 \mathrm{aA}(917,2)$ \\
\hline 91 a 180 & $93,1 \mathrm{aA}(10,8)$ & $94,8 \mathrm{aA}(10,9)$ & $8.379 \mathrm{aA}(612,4)$ & $8.532 \mathrm{aA}(983,4)$ \\
\hline 181 a 270 & $102,2 \mathrm{aA}(12,4)$ & $93,8 \mathrm{aA}(10,5)$ & $9.198 \mathrm{aA}(691,5)$ & $8.442 \mathrm{aA}(879,0)$ \\
\hline Média $^{3}$ & $87,3 \mathrm{a}(9,3)$ & $95,2 \mathrm{a}(11,0)$ & - & - \\
\hline Total $^{3}$ & - & - & $23.382 \mathrm{a}(2.901,2)$ & $25.695 \mathrm{a}(2.912)$ \\
\hline C.V. $(\%)$ & 13,9 & 15,2 & 18,1 & 19,8 \\
\hline
\end{tabular}

${ }^{1}$ Médias seguidas na mesma letra, minúscula na linha e maiúscula na coluna, não diferem entre si, pelo teste de Tukey a 5\% de probabilidade.

2 Valores entre parênteses correspondem ao erro-padrão da média.

3 Valores relativos ao período completo de avaliação (270 dias).

principalmente quanto à realização de adubação, irrigação e controle de plantas invasoras (Tabela 5).

A produção de leite por área é reflexo das produções individuais de leite $(\mathrm{kg} / \mathrm{vaca} / \mathrm{dia})$ e das taxas de lotação da pastagem que se consegue. Há que se considerar que esses dois fatores, além de sofrerem influência dos tratamentos avaliados, são também determinados pela época do ano e pela fase de lactação dos animais. Assim, na primeira fase de avaliação do presente estudo, obteve-se a menor taxa de lotação da pastagem e a menor produção individual de leite nas condições em que as vacas receberam quantidade fixa de concentrado. Conseqüentemente, nessas condições foram registradas as menores $(\mathrm{P}<0,05)$ produções de leite por área $(64,5 \mathrm{~kg} / \mathrm{ha} / \mathrm{dia}$ e $5.805 \mathrm{~kg} / \mathrm{ha} /$ período). Por outro lado, nas fases seguintes, apesar de a fase de lactação corresponder a menores produções individuais de leite, as elevadas taxas de lotação da pastagem, conseguida nesses períodos, favoreceram as produções de leite por área. Os resultados obtidos são semelhantes aos registrados por Vilela et al. (1996) e por Alvim et al. (1997), e superiores aos obtidos por Martinez et al. (1980), que avaliaram a produção de leite de vacas da raça Holandesa em pastagem de coast-cross.

\section{CONCLUSÕES}

1. O fornecimento diário de $6 \mathrm{~kg}$ de concentrado, a vacas da raça Holandesa em pastagem de coast-cross, distribuído em quantidades fixa e variável, na média, resulta em produções de leite que atinge 18,5 e $19,8 \mathrm{~kg} / \mathrm{vaca} / \mathrm{dia}, 87,3$ e $95,2 \mathrm{~kg} / \mathrm{ha} / \mathrm{dia}, 4.995$ e $5.355 \mathrm{~kg} / \mathrm{vaca} / 270$ dias e 23.382 e $25.695 \mathrm{~kg} / \mathrm{ha} / 270$ dias, respectivamente.

2. O fornecimento diário de $6 \mathrm{~kg}$ de concentrado, distribuído em quantidade variável, prolonga o pico de lactação das vacas durante os primeiros 90 dias, mantendo a produção de leite praticamente constante nesse período.

3. O fornecimento variável de concentrado favorece $(\mathrm{P}<0,05)$ a taxa de lotação da pastagem por ocasião do recebimento de maior quantidade do concentrado.

4. O fornecimento diário de $6 \mathrm{~kg}$ de concentrado distribuído em dose variável é mais indicado que o fornecimento em dose fixa. 


\section{REFERÊNCIAS}

ALVIM, M.J.; VILELA, D.; LOPES, R.S. Efeitos de dois níveis de concentrado sobre a produção de leite de vacas da raça Holandesa em pastagem de coast-cross. Revista da Sociedade Brasileira de Zootecnia, Viçosa, MG, v.26, n.5, p.967-975, set./out. 1997.

ARRIGA-JORDAN, C.M.; HOLMES, W. The effect of concentrate supplementation on high-yielding dairy cows under two systems of grazing. Journal of Agricultural Science, Cambridge, v.107, n.2, p.453-461, Oct. 1986.

ASSIS, A.G. Sistema de alimentação de vacas em produção. Coronel Pacheco: Embrapa-CNPGL, 1982. 43p. (Embrapa-CNPGL. Documentos, 7).

BOTREL, M.A.; ALVIM, M.J.; XAVIER, D.F. Avaliação de forrageiras em duas regiões do Campo das Vertentes de Minas Gerais. Revista da Sociedade Brasileira de Zootecnia, Viçosa, MG, v.23, n.2, p.189-196, mar./abr. 1994.

COWAN, R.T. Milk paroduction from grazing systems in the Northern Australia. In: SIMPÓSIO INTERNACIONAL SOBRE O FUTURO DOS SISTEMAS DE PRODUÇÃO DE LEITE NO BRASIL, 1995, Juiz de Fora. Anais. Juiz de Fora: Embrapa-CNPGL, 1996. p.41-49.

DAVIDSON, T.M. The milk production potential of forage-concentrate systems in Queensland. In: $\mathrm{HIGH}$ PRODUCTION PER COW SEMINAR, 1990. Sidney: Queensland Department of Primary Industries, 1990. p.1-13.

MARTINEZ, R.O.; RUIZ, R.; HERRERA, R. Milk production of cows grazing Coast-cross $\mathrm{N}^{\mathrm{o}} 1$ bermuda grass (Cynodon dactylon). I. Different concentrate supplementation levels. Cuban Journal of Agricultural Science, La Habana, v.14, n.2, p.225-232, 1980.

MATOS, L.L. de. Perspectivas em alimentação e manejo de vacas em lactação. In: REUNIÃO ANUAL DA SOCIEDADE BRASILEIRA DE ZOOTECNIA, 32., 1995, Brasília. Anais. Brasília: SBZ, 1995. p.147-155.
MILERA, M.; MARTINEZ, J.; CÁCERES, O.; HERNÁNDEZ, J. Efecto de diferentes ofertas del pasto Cynodon dactylon (L.) Pers. cv. coast-cross-1 sobre la estructura y el valor nutritivo de la planta en pastoreo. Pastos y Forrajes, Matanzas, v.10, n.2, p.239-245, 1987.

MILERA, M.; MARTINEZ, J.; CÁCERES, O.; HERNÁNDEZ, J. Influencia del nivel de oferta en la producción de leche según los dias de estancia en la Bermuda cruzada-1. Pastos y Forrajes, Matanzas, v.9, n.2, p.167-176, 1986.

MOREIRA, H.A. Suplementação de concentrados para vacas leiteiras. 2.ed. Coronel Pacheco, MG: Embrapa-CNPGL, 1984. 14p. (Embrapa-CNPGL. Circular técnica, 17).

NATIONAL RESEARCH COUNCIL. (Washington, DC). Predicting feed intake of food-producing animals. Washington, DC: National Academy Press, 1987. $85 \mathrm{p}$.

STOBBS, T.H. Milk production per cow and per hectare from tropical pastures (milk production from tropical pastures). In: SEMINARIO INTERNATIONAL DE GANADERIA TROPICAL: PRODUCCION DE FORRAJES, 1976, México. Memoria. Ciudad del México: Secretaría de Agricultura e Ganadería/Banco del México, 1976. p.129-146.

TAYLOR, W.; LEAVER, J.D. Systems of concentrate allocation for dairy cattle. 2. A comparison of two patterns of allocation for autumn-calving cows offered two qualities of grass silage ad libitum. Animal Production, Edinburgh, v.39, n.3, p.325-333, Dec. 1984.

VILELA, D.; ALVIM, M.J.; CAMPOS, O.F.; RESENDE, J.C. Produção de leite de vacas Holandesas em confinamento ou em pastagem de coast-cross. Revista da Sociedade Brasileira de Zootecnia, Viçosa, MG, v.25, n.6, p.1228-1244, 1996. 